\title{
THE IMPACT OF MENTAL READINESS ON DRIVING PERFORMANCE AND TRAFFIC SAFETY
}

\author{
NICKI MARQUARDT ${ }^{1}$, CAROLIN HANNIG $^{2} \&$ SANDRA HANNIG $^{2}$ \\ ${ }^{1}$ Rhine-Waal University of Applied Sciences, Kamp-Lintfort, Germany. \\ ${ }^{2}$ Dresden University of Technology, Germany.
}

\begin{abstract}
The construct 'Mental Readiness' has been used to explain variations in peak performance within different task environments. In particular, research, conducted in diverse work settings such as sports, military and medicine, integrated mental readiness dimensions to increase human performance in critical task episodes. Mental readiness is a complex construct which encompasses sub-dimensions such as attentional control, goal-setting, relaxation, activation, self-confidence, self-talk and imagery. So far, mental readiness has not been used to predict traffic safety and driving performance of young drivers in particular. However, young drivers are involved in a huge amount of traffic accidents and therefore represent a major threat to traffic safety. One explanation is that the insufficient driving performance of young drivers is due to a lack of mental readiness when they enter the street. In this paper, we present the development of a mental readiness measure for student drivers. Hence, 167 student drivers were surveyed regarding mental readiness dimensions, driving performance and perceived stress before and after their final driving test. Data analysis revealed acceptable and even excellent internal consistency of these subscales. A validation study with four safety-related criterion measures (objective driving performance, subjective assessment of driving performance, perceived stress during test preparation, and perceived stress during driving test) showed mixed results. While some scales did not significantly correlate with driving behavior and stress indicators, other subscales like attentional control revealed good prediction coefficients. The current results can be used to train young drivers in raising their mental readiness level which could affect driving performance and road safety positively. In addition, the transfer of the central outcomes of this study to other safety-critical task environments, are discussed.

Keywords: Attentional control, driving performance, mental readiness, stress, traffic safety.
\end{abstract}

\section{INTRODUCTION}

Traffic safety is a major issue in modern societies. In Germany, 3459 people lost their life due to traffic accidents in the year 2015 [1]. Especially young and inexperienced drivers play an important role in accident causation. About $14 \%$ of all people killed and $17 \%$ of all people injured were between 18 and 24 years old, while their relative proportion within the general population is just $7.7 \%$ [2]. These numbers call for additional effort in accident prevention with a special focus on inexperienced drivers. From a psychological point of view, a lack of experience in car driving leads to an overload of cognitive resources which reduces the quality of driving performance in areas such as road hazard monitoring, comprehension of dangerous situations and anticipation of forthcoming events [3]. Consequently, a promising strategy to enhance the driving performance of inexperienced drivers is to improve the mental state of these people when they use a car. One psychological construct that might provide a suitable explanation for human performance in car driving is mental readiness.

\subsection{Mental readiness}

The concept 'Mental Readiness' emerged in the field of sports psychology and describes an optimal mental state to perform. According to Orlick and Partington Mental readiness “(...) 
derived from a number of learned mental skills that must be continually practiced and refined for an athlete to perform (...) on a consistent basis"[4].

\subsection{Dimensions of mental readiness}

Based on in-depth interviews with world-class athletes, Orlick identified several mental readiness elements that contribute to sports excellence and high-performance. These elements encompass constructs such as attentional control, goal-setting, relaxation, activation, self-confidence, selftalk and imagery [5].

\subsubsection{Attentional control}

Attentional control is the ability to focus one's attention to relevant task elements and to fight distraction. It contains the elements attentional focus and distraction control. Attentional focus is a mental preparation strategy to direct one's attention to the right stimuli. Distraction control is the ability to deal with possible internal and external distractions during a task [6]. A lot of studies in the field of sports psychology, [4, 7-9], as well as in medicine [10] and music [11] showed a relationship between attentional focus or attentional control and performance increase. A study with golfers has revealed that professional golfers have a higher ability to deal with distractions than novices [12]. Another qualitative study with Canadian Olympic athletes showed that distraction control is important for peak performance [13]. Wang emphasizes that internal, personal and external situational distractions should be controlled [14]. This seems to be important in the context of driving situations too, as there are a lot of internal and external distractions, especially for young and inexperienced drivers.

\subsubsection{Goal setting}

Goal setting is a technique where goals are set to increase and direct motivation [15]. It is one of the most examined techniques to increase performance in the fields of organizations, education and sports [16].

Locke and Latham (1990) developed a motivational theory which describes the influence of goals on performance. They formulated two core assumptions regarding the difficulty and specificity of goals. Locke and Latham assume that challenging goals lead to a higher performance until the ability limit of a person is reached. The second hypothesis states that specific and challenging goals lead to a higher performance than vague or no goals [17]. These assumptions find support in the majority of studies, [e.g. 18, 19], but there is an inconsistency in the field of sports psychology. Some studies e.g. a study with jugglers could not find a relationship between the difficulty of goals and performance [20]. A meta-analysis by Kyllo and Landers indicates that goal setting does lead to an improvement of performance also in the sports sector [21].

In the concept of mental readiness, the importance of specific, realistic and personal goals for the peak performance of athletes is also stressed [5, 12]. We therefore suggest that setting specific and at least realistic goals is also important for young drivers to improve their driving performance.

\subsubsection{Relaxation}

Relaxation and activation are elements of mental readiness and can be described as coping strategies with the aim of successfully handling stressful situations [22]. Both elements are part of a coping strategy named arousal management and are related to the Inverted 
U-Hypothesis which claims that the connection between performance and arousal is curvilinear. The level of arousal should neither be too low not too high in order to achieve performance excellence [23]. To reach excellent performance people need to handle their arousal correctly. One way of reducing overarousal is the use of relaxation strategies [24]. Scientific research divides relaxation strategies into two different kinds: somatic and cognitive techniques. Breathing - a technique which focuses on the right way of breath drawing - as well as Progressive Muscle Relaxation (PMR) by Jacobsen (1993) - a technique which reduces overarousal by focusing on specific body regions and their relaxation - are somatic techniques [25], whereas meditation like the Relaxation Response Technique by Benson (1975) and visualization are cognitive techniques of relaxation strategies [25]. The connection between relaxation strategies and performance is proved in several studies $[4,26]$. Orlick specifically names breathing and PMR as two strategies which lead to mental readiness and thus to performance excellence [5]. We assume that strategies like breathing could help drivers to handle stressful traffic situations.

\subsubsection{Activation}

The terms arousal and activation are often used synonymously. Both terms include cognitive and physical activities. Another common characteristic is that there is no clear connotation of both terms. The main difference between the similar terms of arousal and activation is the planning aspect [23]. Activation includes a planned reaction while arousal is more spontaneous as it is defined as 'the automatic response of the nervous system to (an individual's) mental state' [27]. The Inverted U hypothesis states that underarousal does not lead to performance excellence, either. One strategy to avoid underarousal and produce excellent performance is the so-called preparatory arousal strategy. It is defined as a strategy used to intendedly 'increase the body's level of arousal' [28] by carrying out specific activities [28]. In an example study, Tynes and McFatter instructed weightlifters to emotionally prepare themselves for the weightlifting task by producing specific feelings like anger. Their study proved that preparatory arousal had the biggest effect on the weightlifting performance compared to other strategies [9]. Another example for a technique used in the field of preparatory arousal is fast breathing [29]. Scientific research in sports has shown that not only relaxation strategies like PMR or breathing are important for performance excellence but also different activation strategies might also be helpful. [5, 9]. In the field of traffic and driving performance, activation strategies can have both positive and negative effects. By using anger to get emotionally charged, drivers could easily get overaroused and lose their focus on the driving task. However, using activation strategies could also avoid underarousal which would be beneficial for e.g. long journeys.

\subsubsection{Self-confidence}

Confidence is generally defined as 'a degree of certainty about a perception event or outcome' [30]. In terms of sport, Vealey points out that it is 'the belief or degree of certainty that individuals possess about their ability to be successful in sport' [31]. Several studies in sports prove that self-confidence is one of the major elements of mental readiness which lead to an improved performance $[7,8]$. We assume that a high level of self-confidence could either lead to an increased driving performance or to the opposite, due to the danger of overestimating oneself. Another important concept which is related to self-confidence and enhanced performance is called self-efficacy. Self-efficacy focuses on people's beliefs of what they can reach with their own capabilities [32]. It is considered as a situation depending 
type of self-confidence. People with a high degree of self-efficacy are convinced to perform well in a specific situation e.g. a sports tournament [33]. Lohasz and Leith for example show that self-efficacy had an important effect on athletes' performances in different kinds of sports [6].

\subsubsection{Self-talk}

One source of self-confidence is the so-called self-regulation. By self-talk can be understood as a specific self-regulative technique in which people speak to themselves with the aim of controlling and managing their thoughts [34]. Scientific research comes to the conclusion that self-talk is a strategy which on the one hand enhances self-confidence [e.g. 31] and on the other hand also enhances performances directly. Ming \& Martin for example revealed this in a study with figure skaters. The participants were convinced that using self-talk improved their performance [35]. It is possible that the use of self-talk enables drivers to refocus on their driving task and thus leads to a better driving performance.

\subsubsection{Imagery}

The relationship between imagery and performance has been examined in several studies especially in the field of sport psychology [4, 12] but also in medicine [10]. Imagery is defined as 'using all the senses (...) to create or re-create an experience in the mind' [36]. Hackfort and Munzert stated that imagery is a mostly visual and kinesthetic form of mental simulation whereby individuals use an internal representation of situations to mentally prepare for actions that they want to organize or perform [24]. Imagery can have two modes, a replay and a preplay mode. If it is performed in a replay mode, it means that 'an inner (mental) repetition of actions, situations and events' [24] takes place which can be used to analyze these and for example identify errors. In the preplay mode, events are anticipated before they actually happen [24]. The ability to imagery and its links to the dimensions vividness and controllability is also part of the mental readiness research. Highly vivid and controlled imagery leads to a higher performance in sports [10,4]. Another part of imagery that is highly focused on is the perspective of imagery, which can be either internal or external. In comparison to the external perspective where individuals see themselves from the outside, individuals imagine situations and events from their own point of view when using the internal perspective. Elite athletes rather use the internal than the external view compared to nonelite athletes [4, 37]. Currently, there is no research conducted that examines if imagery, as a part of mental readiness, can contribute to higher performances of young drivers, but based on the previously described empirical findings we do assume so.

\section{THE PRESENT STUDY}

Until now, mental readiness has not been used to explain traffic safety and driving performance of inexperienced drivers. However, as mentioned above, young drivers are involved in many traffic accidents and therefore represent a threat to traffic safety. One explanation for the deficient driving performance of inexperienced drivers is the lack of mental readiness while driving a car. To obtain a sufficient performance level, the driver must have a good mental readiness to cope with stressful traffic situations (by using relaxation, self-talk and activation strategies), to recognize road hazards and fast situation changes in good time (by gaining adequate attentional control, visual imagery and warding off distraction), and to accomplish complex psycho-motor steering tasks in dynamic traffic environments (by the use of goal setting, attentional processes and self-confidence). 
In this study, we developed a mental readiness measure for student drivers to explain differences in driving performance and potential traffic risks. Student drivers were selected as an appropriate sample because of their very low level of driving experience.

\section{METHOD}

\subsection{Participants}

Two hundred and sixty-one student drivers were surveyed regarding their level of mental readiness during driving lessons and the final driving test as well as the respective driving performance and stress. One hundred and sixty-seven valid questionnaires were returned. The average age was $22.87(\mathrm{SD}=9.22) ; 55 \%$ of the participants were female and $44 \%$ were male.

\subsection{Materials}

A questionnaire was developed that consisted of two parts. Part one comprised the Mental Readiness Scale (MRS) which included 71 Likert-items with a seven-point-scale ( $1=$ totally disagree -7 = totally agree), specifically designed for mental readiness aspects in car driving. The MRS encompasses seven sub-scales: goal-setting (12 items), attentional control (9 items), relaxation (9 items), activation (6 items), imagery (17 items), self-confidence (8 items) and self-talk (10 items) (see Table 1). The second part of the questionnaire contained four criterion measures: Subjective and objective driving performance and perceived stress (during driving test preparation and during driving test). Subjective driving performance was rated on a seven-point scale $(1=$ very bad -7 = very good). Objective driving performance was rated on a dichotomous scale $(1=$ passed the driving test $-2=$ failed the driving test $)$. Perceived stress

Table 1: Seven sub-scales of the MRS.

\begin{tabular}{|c|c|}
\hline Sub-scale & Example items \\
\hline Goal setting & $\begin{array}{l}\text { - I set goals that challenge me. } \\
\text { - Ifelt motivated by my own goals. }\end{array}$ \\
\hline $\begin{array}{l}\text { Attentional } \\
\text { control }\end{array}$ & $\begin{array}{l}\text { - When I made a mistake during the test I had problems in regaining } \\
\text { focused attention. (-) } \\
\text { - It was easy to control disturbing minds during my test preparation. }\end{array}$ \\
\hline Relaxation & $\begin{array}{l}\text { - During test completion I was able to relax. } \\
\text { - I spared to use relaxation techniques during test preparation. (-) }\end{array}$ \\
\hline Activation & $\begin{array}{l}\text { - I could psych-up myself when I was tired. } \\
\text { - I obtained my optimal energy level during test completion. }\end{array}$ \\
\hline Imagery & $\begin{array}{l}\text { - Shortly before the test, I rehearsed all the procedural steps in my mind. } \\
\text { - Prior to my test, I mentally simulated what to do when problems arose. }\end{array}$ \\
\hline Self-confidence & $\begin{array}{l}\text { - Even when problems arose within the test, I believed I could accomplish } \\
\text { the task. } \\
\text { - I was convinced I could attain my goals because of my competence. }\end{array}$ \\
\hline Self-talk & $\begin{array}{l}\text { - The key words I used supported me in my task. } \\
\text { - During test preparation I talked to myself. }\end{array}$ \\
\hline
\end{tabular}

$(-)=$ negatively keyed items 
(during driving test preparation) was rated on a seven-point scale $(1=$ highly stressed $-7=$ very relaxed). Perceived stress (during driving test) was rated on a seven-point scale $(1=$ highly stressed $-7=$ very relaxed).

\section{RESULTS}

\subsection{Reliability of the MRS}

Table 2 summarizes the reliability coefficients (internal consistency measured in Cronbach's $\alpha$ ) of the seven Mental Readiness sub-scales. As can be seen, the reliabilities ranged from low (e.g. relaxation scale) to very high (self-confident scale). After the reduction of items with low item-total-correlations, the internal consistency of some scales could be improved (e.g. the imagery scale moved from 0.59 to 0.82 ).

\subsection{Criterion-validity of the MRS}

Table 3 shows the criterion-validity of the single mental readiness scales. The table reveals huge variance in the correlations between the mental readiness scales and the four criterion variables. Attentional control, for instance, is the only scale within the MRS which correlates significantly with all four criterions. Moreover, attentional control is the only measure that is significantly related to the objective performance criterion, the passed driving test. On the contrary, self-talk and relaxation do not correlate significantly with any criterion measure at all. Other scales such as imagery seem to be related to stress criterions but not to performance indicators, whereas activation seems to affect the subjective driving performance evaluation but not the perceived stress level.

\section{DISCUSSION}

\subsection{Interpretation of results}

As has been shown in Table 3, the study produced mixed results. It seems that not all mental readiness dimensions equally contribute to driving performance and stress reduction.

Table 2: Reliability of the seven sub-scales of the MRS.

\begin{tabular}{lllll}
\hline Scale & $\begin{array}{l}\text { Item } \\
\text { number }\end{array}$ & Cronbachs' $^{\prime} \alpha$ & $\begin{array}{l}\text { Item number } \\
\text { (after item } \\
\text { reduction) }\end{array}$ & $\begin{array}{l}\text { Cronbachs' } \alpha \\
\text { (after item } \\
\text { reduction) }\end{array}$ \\
\hline Goal-setting & 12 & 0.67 & 9 & 0.74 \\
Attentional control & 9 & 0.83 & 9 & 0.83 \\
Relaxation & 9 & 0.58 & 8 & 0.61 \\
Activation & 6 & 0.66 & 5 & 0.68 \\
Imagery & 17 & 0.59 & 13 & 0.82 \\
Self-confidence & 8 & 0.90 & 8 & 0.90 \\
Self-talk & 10 & 0.68 & 8 & 0.77 \\
MRS-total score & 71 & 0.88 & 60 & 0.89 \\
\hline
\end{tabular}


Table 3: Criterion-validity of the seven sub-scales of the MRS with four criterions.

\begin{tabular}{lclll}
\hline & $\begin{array}{l}\text { Perceived } \\
\text { stress (during } \\
\text { test prepara- } \\
\text { tion) }\end{array}$ & $\begin{array}{l}\text { Perceived } \\
\text { stress (during } \\
\text { driving test) }\end{array}$ & $\begin{array}{l}\text { Subjective } \\
\text { performance } \\
\text { (self-evaluation of } \\
\text { driving } \\
\text { performance) }\end{array}$ & $\begin{array}{l}\text { Objective } \\
\text { performance } \\
\text { (passed } \\
\text { driving test) }\end{array}$ \\
\hline Goal-setting & $0.18^{*}$ & 0.00 & $0.27^{* *}$ & -0.07 \\
Attentional control & $0.36^{* *}$ & $0.47^{* *}$ & $0.49^{* *}$ & $-0.17^{*}$ \\
Relaxation & -0.08 & 0.12 & 0.06 & 0.06 \\
Activation & 0.13 & 0.09 & $0.29^{* *}$ & -0.06 \\
Imagery & $-0.19^{*}$ & $-0.16^{*}$ & 0.07 & -0.05 \\
Self-confidence & $0.44^{* *}$ & $0.43^{* *}$ & $0.46^{* *}$ & -0.09 \\
Self-talk & -0.09 & -0.08 & 0.06 & 0.03 \\
MRS-total score & $0.17^{*}$ & $0.20^{*}$ & $0.39 * *$ & -0.12 \\
\hline
\end{tabular}

Significance level: $* \mathrm{p}<0.05 ; * * \mathrm{p}<0.01 ; * * * \mathrm{p}<0.001$.

Given the assumption that a lower stress level and a good driving performance of inexperienced drivers are positively related to traffic safety, attentional control is the most important dimension of the mental readiness construct. Other mental readiness aspects such as relaxation and self-talk might not be relevant for inexperienced drivers in respect of their driving performance improvements and stress remediation. Furthermore, scales like imagery are negatively correlated with stress indicators. Probably, the mental activity to rehearse procedural steps and anticipate problems in one's mind seems to demand cognitive resources which are urgently needed for the driving task. Therefore, the visual imagery seems to overload the cognitive capacity of inexperienced drivers within the driving task.

To sum up, the most effective way for inexperienced drivers to reduce stress and raise their driving performance level is to learn how to focus one's attention and to ward off distractions within traffic situations.

\subsection{Strengths and limitations}

Like all research, this study has both strengths and limitations. One strength is the novelty of applying a human performance construct from sports psychology to the field of safety research. As mentioned above, mental readiness has been used to explain variations in peak performance of athletes but never for car drivers. With respect to the correlations between the mental readiness scales and the four criterions which are important for road safety, there is evidence that mental readiness dimension are relevant for inexperienced car drivers. In addition, the reliability of most scales was good. The internal consistency ranged between Cronbach's $\alpha=0.61-0.90$.

Beside these strengths, there are also some noteworthy limitations. First, all criterion measures were only proxy-measures of traffic safety. In this survey, there was no opportunity to assess the real driving performance and to collect safety-critical incidents such as near accidents, risky driving passing maneuvers or delayed hard breaking. Furthermore, the internal consistency of the relaxation and the activation scale should be improved. 


\subsection{Implications for future research}

This study has shown that mental readiness dimensions have an effect on driving performance and perceived stress of inexperienced car drivers. Future research should focus on the relation of attentional control and driving performance as well as stress indicators. A promising research strategy might be to measure the level of attentional control and to test the driving performance and stress effects in driving simulator experiments by recording safety-relevant indicators (e.g. near accidents, risky driving passing maneuvers, delayed hard breaking, recognition of sudden situation changes). Additional measures such as eye-tracking or EEG-data could be used to validate the attentional control sub-scale. This could be a useful step to develop better driving trainings which support inexperienced drivers to allocate their attention effectively. Finally, this research strategy could also be transferred to other safety-critical industries where mental readiness might be important. For example, monitoring tasks in chemical plants or surgical performance within medical operating rooms - for both task environments there are experimental simulators in these industries - could be analyzed with regard to mental readiness dimensions.

\section{REFERENCES}

[1] Statistisches Bundesamt. (n.d.). Anzahl der Verkehrstoten im Straßenverkehr in Deutschland von 1991 bis 2015. In Statista - Das Statistik-Portal, 2015, available at https:// de.statista.com/statistik/daten/studie/185/umfrage/todesfaelle-im-strassenverkehr/. (accessed 29 November 2016).

[2] DeutscherVerkehrssicherheitsrat, available at http://www.dvr.de/betriebe_bg/daten/ unfallstatistik/de_jungeerwachsene.htm. (accessed 29 November, 2016).

[3] Hoeger, R., Seidenstücker, J. \& Marquardt, N., Mental models and attentional processes in car driving. Driver Behavior and Training II, ed L. Dorn, Aldershot (UK): Ashgate, pp. 443-449, 2005.

[4] Orlick, T. \& Partington, J., Mental links to excellence. The Sport Psychologist, 2, pp. 105-130, 1988.

https://doi.org/10.1123/tsp.2.2.105

[5] Orlick, T., In Pursuit of Excellence. How to Win in Sport and Life through Mental Training. Human Kinetics: Champaign, 2000.

[6] Lohasz, P.G. \& Leith, L.M., The effect of three mental preparation strategies on the performance of a complex response time task. International Journal of Sport Psychology, 28, pp. 25-34, 1997.

[7] Gould, D., Weiss, M.R. \& Weinberg, R.S., Psychological characteristics of successful and nonsuccessful Big-Ten wrestlers. Journal of Sport Psychology, 3, pp. 69-81, 1981. https://doi.org/10.1123/jsp.3.1.69

[8] Mahoney, M.J., Gabriel, T.J. \& Perkins, T.S., Psychological skills and exceptional athletic performance. The Sport Psychologist, 1, pp. 181-199, 1987. https://doi.org/10.1123/tsp.1.3.181

[9] Tynes, L.L. \& McFatter, R.M., The efficacy of "Psyching" strategies on a weight-lifting task. Cognitive Therapy and Research, 11, pp. 327-336, 1987. https://doi.org/10.1007/bf01186283 
[10] McDonald, J., Orlick, T. \& Letts, M., Mental readiness in surgeons and its links to performance excellence. Surgery, Journal of Pediatric Orthpaedics, 15, pp. 691-697, 1995.

https://doi.org/10.1097/01241398-199509000-00027

[11] Talbot-Honeck, C. \& Orlick, T., The essence of excellence: mental skills of top classical musicians. Journal of Excellence, 1, pp. 61-75, 1998.

[12] McCaffrey, N. \& Orlick, T., Mental factors related to excellence among top professional golfers. International Journal of Sport Psychology, 20, pp. 256-278, 1989.

[13] Gould, D., Greenleaf, C., Guinan, D., Dieffenbach, K. \& McCann, S., Pursuing performance excellence: lessons learned from olympic athletes and coaches. Journal of Excellence, 4, pp. 21-43, 2001.

[14] Wang, J., Mental strategies for peak performance. Strategies: A Journal for Physical and Sport Educators, 19, pp. 22-25, 2006.

https://doi.org/10.1080/08924562.2006.10591201

[15] Filby, W.C.D., Maynard, I.W. \& Graydon, J.K., The effect of multiple-goal strategies on performance outcomes in training and competition. Journal of Applied Sport Psychology, 11, pp. 230-246, 1999.

https://doi.org/10.1080/10413209908404202

[16] Weinberg, R., Burton, D., Yukelson, D. \&Weigand, D., Goalsetting in a competitive sport: An exploratory inverstigation of practicers of collegiate athletes. The Sport Psychologist, 7, pp. 275-289, 1993.

https://doi.org/10.1123/tsp.7.3.275

[17] Locke, E.A. \& Latham G.P., Goalsetting theory, 1990 (Chapter 1), New Developments in Goalsetting and Task Performance, eds. E.A. Locke \& G.P. Latham, Routledge: New York, pp. 3-15, 2013.

[18] Locke, E.A., Relation of goallevel to performance with a short work period and multiple goal levels. Journal of Applied Psychology, 67, pp. 512-514, 1982.

https://doi.org/10.1037/0021-9010.67.4.512

[19] Lerner, B.S. \& Locke E.A., The effects of goal setting, self-efficacy, competition and personal traits on the performance of an endurance task. Journal of Sport and Excerise Psychology, 17, pp. 138-152, 1995.

https://doi.org/10.1123/jsep.17.2.138

[20] Anshel, M.H., Weinberg, R. \& Jackson, A., The effect of goal difficulty and task complexity on intrinsic motivation and motor performance. Journal of Sport Behavior, 15, pp. 159-176, 1992.

[21] Kyllo, L.B. \& Landers, D.M., Goal setting in sport and excerise: A research synthesis to resolve the controversy. Journal of Sport and Excerise Psychology, 17, pp. 117-137, 1995. https://doi.org/10.1123/jsep.17.2.117

[22] Crocker, P.R.E. \& Graham, T.R., Coping by competitive athletes with stress: gender differences and relationships with affect. The Sport Pschologist, 9, pp. 325-336, 1995. https://doi.org/10.1123/tsp.9.3.325

[23] Hardy, L., Jones, J.G. \& Gould, D., Understanding psychological preparation for sport: theory and practice of elite performers. Wiley \& Sons: Chichester, 1996.

[24] Hackfort, D. \& Munzert, J., Mental Simulation (Chapter 1). Handbook of research in applied sport and excercise psychology: international perspective, eds. D. Hackfort, J.L. Duda \& R. Lidor, Sheridan Books: Morgentown, pp. 3-18, 2005. 
[25] Williams, J.M. \& Harris, D.V., Relaxation and energizing techniques for regulation of arousal (Chapter 15). Applied Sport Psychology: Personal Growth to Peak Performance, ed. J.M. Williams, McGraw-Hill: New York, pp. 285-305, 2006.

[26] Hall, E.G. \& Hardy, C.J., Ready, aim, fire - Relaxation strategies for enhancing pistol marksmanship. Perceptual and Motor Skills, 72, pp. 775-786, 1991. https://doi.org/10.2466/pms.72.3.775-786

[27] Hermery, D., The pursuit of sporting excellence. A study of sport's highest achievers. Human Kinetics Books: Champaign, 1986.

[28] Parker, L. Sealey, R.M. \& Swimbourne, A., The effect of prepatory arousal on hand grip strength and 50 metre freestyle swim performance_paper, available at http://digitalcommons.wku.edu/cgi/viewcontent.cgi?article=1273\&context=ijesab (accessed 9 March 2017).

[29] Zaichkowsky, L.D. \& Baltzell, A., Arousal and performance (Chapter 12). Handbook of Sport Psychology. Second Edition, eds. R.N. Singer, H.A. Hausenblas \& C.M. Janelle, Wiley \& Sons: New York, pp. 319-339, 2001.

[30] Cramer, R.J., Neal, T.M.S. \& Brodsky, S.L., Self-efficacy and confidence: theoretical distinctions and implications for trial consultation. Consulting Psychology Journal: Practice and Research, 61, pp. 319-334, 2009. https://doi.org/10.1037/a0017310

[31] Vealey, R.S., Understanding and enhancing self-confidence in athletes (Chapter 22). Handbook of sport psychology. Second Edition, eds. R.N. Singer, H.A. Hausenblas \& C.M. Janelle, Wiley \& Sons: New York, pp. 550-565, 2001.

[32] Bandura, A., Social Foundations of Thought and Action: A Social Cognitive Theory. Englewood Cliffs, NJ: Prentice-Hall, 1986.

[33] Gill, D.L. \& Williams, L., Psychological Dynamics of Sport and Excercise. Third Edition. Human Kinetics: Champaign, 2008.

[34] Bull, S.J., Albinson, J.G. \& Shambrook, C.J., The Mental Game Plan: Getting Psyched for Sport. Sports Dynamics: Eastbourne, 1996.

[35] Ming, S. \& Martin, G.L., Single-subject evaluation of a self-talk package for improving figure skating performance. The Sport Psychologist, 10, pp. 227-238, 1996. https://doi.org/10.1123/tsp.10.3.227

[36] Weinberg, R., Does imagery work? effects on performance and mental skills. Journal of Imagery Research in Sport and Physical Activity, 3, pp. 1-21, 2008. https://doi.org/10.2202/1932-0191.1025

[37] Mahoney, M.J. \& Avener, M., Psychology of the elite athlete: an exploratory study. Cognitive Therapy and Research, 1, pp. 135-141, 1977. https://doi.org/10.1007/bf01173634 